
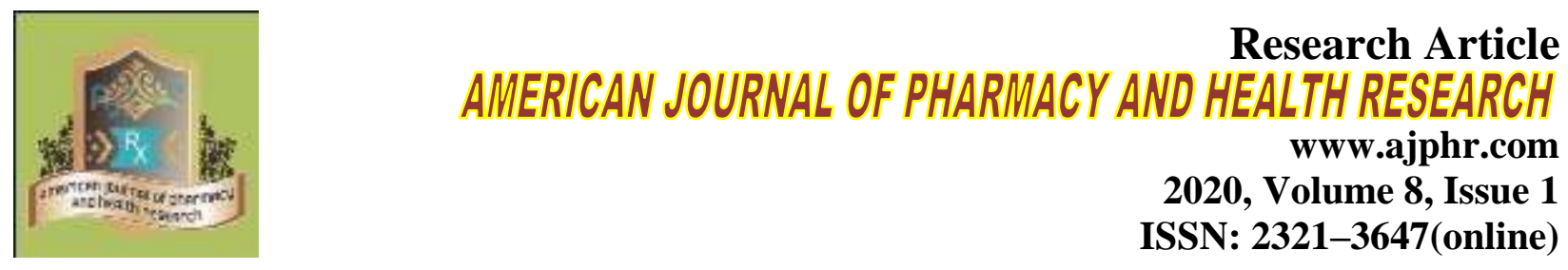

\title{
Impact of Maternal Employment On Child Survival in India in The Era of Sustainable Development Goals
}

\author{
Preethi Karunakaran* \\ Department of Demography, University of Kerala, India
}

\begin{abstract}
Remarkable achievements have been made in the last few decade to reduce the child mortality worldwide. The increased reach of health programs in India throughout the past few decades has contributed to a decline in postnatal mortality as well as child and infant mortality but, reduction in under 5 mortality remained negligible. In this paper I explored, to what extent the participation of mothers in the work force influences the under-five mortality. The specific objectives are to explain the trend of survival of children in India and to trace the linkage between maternal employment and child survival in India. The present paper critically analyses the impact of mother's work standing on under 5 mortality using highly reliable data collected from the recent NFHS conducted in 2015-16. The study population is comprised of children aged 0 to 59 months and born to mothers aged 15 to 49 years. Life Table techniques and Survival curve was used to trace the association of maternal employment on survival of children. The under-five mortality showed a consistent decrease in India from 1992 to 2015. The results showed that high risk of mortality is identified more among children of non-working mothers rather than working.
\end{abstract}

Keywords: Child health, dual role of mother, maternal employment, motherhood, sustainable development goal, under-five mortality. 


\section{INTRODUCTION}

The post-2015 era marked the start of Sustainable development goals (SDGs) (UN, 2015). Child mortality has been the hub of health discourse since time immemorial. Governments, health professionals, and policymakers have reserved a particular interest in reducing the prevalence of childhood deaths globally (Oyewale et al.,2017). This interest has been led to the development of sound interventions to reducing child mortality among children under- five years of age between 1990 and 2015, and between 2015 and 2030 as tagged in the United Nation's Millennium Development Goals (MDGs), and Sustainable Development Goals (SDGs) respectively (UN, 2015).

Based on the reports of 1992, 1998, and 2005, National Family Health Surveys, the risk of under-five mortality shows decline over time. This decline is due to the continuous and consistent implementation of the health policy interventions, but the reduction in under-five mortality remained negligible. Even though there were considerable interventions and monitoring mechanisms, still health remains a critical area that needs improvement. The children under- five years of age are vulnerable to many health issues, and their survival is hence to be importantly studied.

Identifying the determinants of under-five mortality (U5M) is essential for formulating appropriate health programs and policies in order to meet the United Nations Millennium Development goal (i.e., to reduce childhood mortality by two-third by 2015). Several studies have been examined the determinants of Under-five mortality. Many studies have identified strong associations between maternal factors and childhood mortality. The dilemmas working mothers face as they attempt to perform dual roles of mothering and working is being realized increasingly in our society. Very few studies in India have specifically investigated the effect of mothers' work on child survival.

Many of the earlier studies suggest two mutually compensating effects of women's work participation on child survival and care (Kishor Sunitha,1998; Glazer,1988). The first one is the positive effect accruing from the mother's income. The mother's work participation enhances the family income, which in turn has a positive impact on child nutrition and health. The labour force participation of the mother can have an adverse effect on child health as the child may not get full attention from its mother and may even have to forego the benefits of breastfeeding. Hence, whether the net effect is positive or negative would be context-dependent. However, the findings under which effects are positive or negative are not always clear. 
The impact of a woman's work on the health and well-being of her children and family is complex, and involves a potential for both positive and negative effects. One of the targets for the third and fifth Sustainable Development Goals (SDGs) borders on children's survival and women's economic empowerment, respectively. A robust investigation of the relationship between maternal employment and childhood mortality will provide information useful for programs aimed at ensuring the achievement of SDG 3 (healthy life for all) and SDG 5 (gender equality, girls, and women empowerment). In India, the studies, mainly focusing on assessing the double burden or double blessing of motherhood and employment is lacking. The proportion of working mothers with younger children is increasing tremendously, but there is no consensus on whether the mother's work status has any adverse effect on child survival in India. In this paper I made an attempt to find out, to which extent the participation of mothers in the work force influences the under-five mortality. The specific objectives are to explain the trend of survival of children in India and to trace the linkage between maternal employment and child survival in India.

\section{MATERIALS AND METHOD}

\section{Data}

This study was based on National Family Health Survey -4, 2015-16. The data were extracted from Kids File. Data was obtained from the most recent live under-5 births from mothers within 5 years prior to the survey. A sample of 259627 births were included in the data out of it, 11884 deaths (4.6 percentage) were reported. Under-5 mortality, death of the children from day of birth to fifth birthday of child was the outcome variable in this study.

\section{Methodology}

Survival analysis such as Life Table techniques and K M Curve used to represent the risk of survival of children in India. The hazard is the instantaneous event (death) rate at a particular time point t. In survival analysis doesn't assume the hazard is constant over time. The total hazard is the cumulative hazard experienced up to time t. The survival function is probability an individual survives up to and including time t. It's the probability that the event (e.g., death) hasn't occurred yet. The Kaplan-Meier curve estimates the survival curve of patients representing the proportion of patients who survived over time. All children between 0 and 59 months of age were included in the estimation and exposure time, and cases were observed during this time frame, with all living children 59 months or younger being considered as 
exposures, contributing person-time, and all deaths among children 59 months or younger regarded as cases.

the age of the child in months was calculated as follows: IF $(\mathrm{B} 5=0)$ age $=\mathrm{B} 7$ and IF $(\mathrm{B} 5=1)$ age $=\mathrm{V} 008-$ B3 where B5 is the survival status of children, V008 is the century month code (CMC) of the date of interview, and B3 is the CMC for date of birth of the child since NFHS calculated age for children by subtracting the month and year of birth from the month and year of interview to give age in month. In the case of under -five mortality, we considered the variable B7 which is the date of death of the children under five years of age.

\section{Life Table}

This study compute cohort measures of mortality. In other words, we follow the children in our subsample from birth and compute probabilities of dying during consecutive age intervals, using the traditional Life-table method. The advantage of the synthetic cohort approach is that mortality probabilities can be readily calculated for time periods close to the survey dat. The lifetable computation uses 16 age intervals: 0 months, 1-2 months, 2-3 months, 4-5 months6-8 months, 9-11 months, 12-17 months, 18-23 months, 24-35 months, 36-47 months, and 48-59 months. In age intervals (duration of survival) each age interval, up to age one, interval is in months and after that the interval is one year.

From these, the following commonly used measures of mortality during infancy and childhood are computed.ie, we considered the classification of under-five mortality as given below. Neonatal mortality (NNM): The probability of dying in the first month of life $(0-1 \mathrm{month})$ Post neonatal mortality (PNNM): The probability of dying in the 2 nd through 11 th month

\section{(IMR-NNM)}

Infant mortality $\left({ }_{1} \mathrm{q}_{0}\right)$ IMR: The probability of dying before the first birthday (0-11 months)

Early child Mortality $\left({ }_{1} \mathrm{q}_{1}\right)$ : The probability of dying between the age 1 and 2 years

Late child mortality: The probability of dying between ages 2 years and 5 years $\left({ }_{3} q_{2}\right)$

Child mortality $\left({ }_{4} \mathrm{q}_{1}\right)$ : The conditional probability of dying between the first and fifth Birthday for those who survive the first year

Under-five mortality $\left({ }_{5} q_{0}\right)$ : The probability of dying before the fifth birthday

\section{RESULTS AND DISCUSSION}


Table. 1: Neonatal, post neonatal, infant, child, and under-five mortality rates for the fiveyear period preceding the survey, from NFHS1 to NFHS 4 (1992-2015)

\begin{tabular}{llllll}
\hline PERIOD & $\begin{array}{l}\text { Neonatal } \\
\text { mortality } \\
\text { (NN) }\end{array}$ & $\begin{array}{l}\text { Post neonatal } \\
\text { mortality } \\
\text { (PNN) }\end{array}$ & $\begin{array}{l}\text { Infant } \\
\text { mortality } \\
(\mathbf{1 q 0})\end{array}$ & $\begin{array}{l}\text { Child } \\
\text { mortality } \\
\mathbf{( 4 q 1 )}\end{array}$ & $\begin{array}{l}\text { Under-five } \\
\text { mortality } \\
(\mathbf{5 q 0})\end{array}$ \\
\hline URBAN & & & & & \\
NFHS-4 & 20.1 & 8.4 & 28.5 & 6.0 & 34.4 \\
NFHS-3 & 28.5 & 13.0 & 41.5 & 10.6 & 51.7 \\
NFHS-2 & 31.7 & 15.4 & 47.0 & 16.9 & 63.1 \\
NFHS-1 & 34.1 & 22.0 & 56.1 & 19.6 & 74.6 \\
RURAL & & & & & \\
NFHS-4 & 33.1 & 12.4 & 45.5 & 10.7 & 55.8 \\
NFHS-3 & 42.5 & 19.7 & 62.2 & 21.0 & 82.0 \\
NFHS-2 & 46.7 & 26.6 & 73.3 & 32.8 & 103.7 \\
NFHS-1 & 52.9 & 32.2 & 85.0 & 37.6 & 119.4 \\
TOTAL & & & & & \\
NFHS-4 & 29.8 & 12.3 & 42.1 & 9.4 & 49.6 \\
NFHS-3 & 39.0 & 18.0 & 57.0 & 18.4 & 74.3 \\
NFHS-2 & 43.4 & 24.2 & 67.6 & 29.3 & 94.9 \\
NFHS-1 & 48.6 & 29.9 & 78.5 & 33.4 & 109.3 \\
\hline
\end{tabular}

Source: Prepared by using data from Different phases of NFHS.

Evidence-based knowledge of trends and drivers of child mortality will aid proper interventions needed to combat the menace. Therefore in this table I made an attempt to trace the trend in early childhood mortality during different phases of NFHS data. This table clearly depicts the decreasing trend in all the categories of early childhood mortality, the neonatal mortality was decreased from 48.6 during the NFHS-1 to 29.8 in NFHS-4. The Rural urban differentials are also visible in this table. More than half decrease happened in the under-five mortality (109.3 t0 49.6) due to the innovative achievements in the Maternal and child Health initiatives of government of India. 
Table 2 Life table estimates of mortality for selected age intervals, for births during the 5 years before the NFHS, 2015-16

\begin{tabular}{|c|c|c|c|c|c|c|c|c|c|}
\hline $\begin{array}{l}\text { Duratio } \\
\text { n of } \\
\text { survival }\end{array}$ & $\begin{array}{l}\text { Actual } \\
\text { no } \\
\text { enterin } \\
\mathrm{g} \text { in this } \\
\text { interval }\end{array}$ & $\begin{array}{l}\text { No. of } \\
\text { withdraw } \\
\text { n during } \\
\text { the } \\
\text { interval }\end{array}$ & $\begin{array}{l}\text { No. of } \\
\text { exposed of } \\
\text { risk }\end{array}$ & $\begin{array}{l}\text { No of } \\
\text { termi } \\
\text { nal } \\
\text { events }\end{array}$ & $\begin{array}{l}\text { Proportion } \\
\text { terminatin } \\
\mathrm{g}\end{array}$ & $\begin{array}{l}\text { Proportio } \\
\text { n } \\
\text { surviving }\end{array}$ & $\begin{array}{l}\text { Cumulative } \\
\text { proportion } \\
\text { (Survival } \\
\text { function) }\end{array}$ & $\begin{array}{l}\text { Probabi } \\
\text { lity } \\
\text { density } \\
\text { function }\end{array}$ & $\begin{array}{l}\text { Hazard } \\
\text { rate }\end{array}$ \\
\hline $0-1$ & 259627 & 1774 & 258740.00 & 7715 & .029818 & .970182 & .970182 & .029818 & .030269 \\
\hline $1-2$ & 250138 & 3823 & 248226.50 & 785 & .003162 & .996838 & .967114 & .003068 & .003167 \\
\hline $2-3$ & 245530 & 4073 & 243493.50 & 486 & .001996 & .998004 & .965184 & .001930 & .001998 \\
\hline $3-4$ & 240971 & 4284 & 238829.00 & 419 & .001754 & .998246 & .963491 & .001693 & .001756 \\
\hline $4-5$ & 236268 & 4405 & 234065.50 & 243 & .001038 & .998962 & .962490 & .001000 & .001039 \\
\hline $5-6$ & 231620 & 4483 & 229378.50 & 185 & .000807 & .999193 & .961714 & .000776 & .000807 \\
\hline $6-7$ & 226952 & 4351 & 224776.50 & 279 & .001241 & 998759 & .960520 & .001194 & .001242 \\
\hline $7-8$ & 222322 & 4402 & 220121.00 & 139 & .000631 & .999369 & .959914 & .000607 & .000632 \\
\hline $8-9$ & 217781 & 4453 & 215554.50 & 168 & .000779 & .999221 & .959166 & .000748 & .000780 \\
\hline $9-10$ & 213160 & 4322 & 210999.00 & 143 & .000678 & .999322 & .958516 & .000650 & .000678 \\
\hline $10-11$ & 208695 & 4079 & 206655.50 & 77 & .000373 & .999627 & .958159 & .000357 & .000373 \\
\hline $11-12$ & 204539 & 3846 & 202616.00 & 63 & .000311 & .999689 & .957861 & .000298 & .000311 \\
\hline $12-24$ & 200630 & 53309 & 173975.50 & 898 & .005162 & .994838 & .952916 & .004944 & .005175 \\
\hline $24-36$ & 146423 & 49408 & 121719.00 & 198 & .001627 & .998373 & .951366 & .001550 & .001628 \\
\hline $36-48$ & 96817 & 51401 & 71116.500 & 71 & .000998 & .999002 & .950417 & .000950 & .000999 \\
\hline $48-59$ & 45345 & 45330 & 22680.000 & 15 & .000661 & .999339 & .949788 & .000000 & .000000 \\
\hline
\end{tabular}

Survival Analysis of children born during 2015-16 in India and its union territories are shown in the table 2.The life table was calculated for the five years of life of children. In India 259627 birth were reported during this period among which 30 deaths/1000 live births were happened during their first month of life. This means that one in 33 live births died during the neonatal period. From the life table the probability of deaths in the first month, first year and under five years of life were calculated as follows;

$$
\begin{aligned}
& 1-S(1)=1-.970182=0.029818 \\
& 1-S(12)=1-0.957861=0.0421
\end{aligned}
$$

$1-\mathrm{S}(24)=1-0.952916=0.0470$

$1-\mathrm{S}(36)=1-.951366=0.04863$

$1-\mathrm{S}(48)=1-.950417=0.04958$

That is, the IMR is 42.1 deaths per 1000 live births. Out of this the NMR is 29.8 and PNMR is 11.3 which indicates that a lion share of the total infant deaths are occurring during their first month of life. Under- five mortality is 50/1000 live births in India. That means, one in every 20 births dies before they attain their fifth birthday. The hazard rate was 30/1000 live births ( 1 in 
every 33 births) which pointed out that the risk of dying during the first month of life of a new born baby was very high in India.

\section{Kaplan-Meier Survival Analysis}

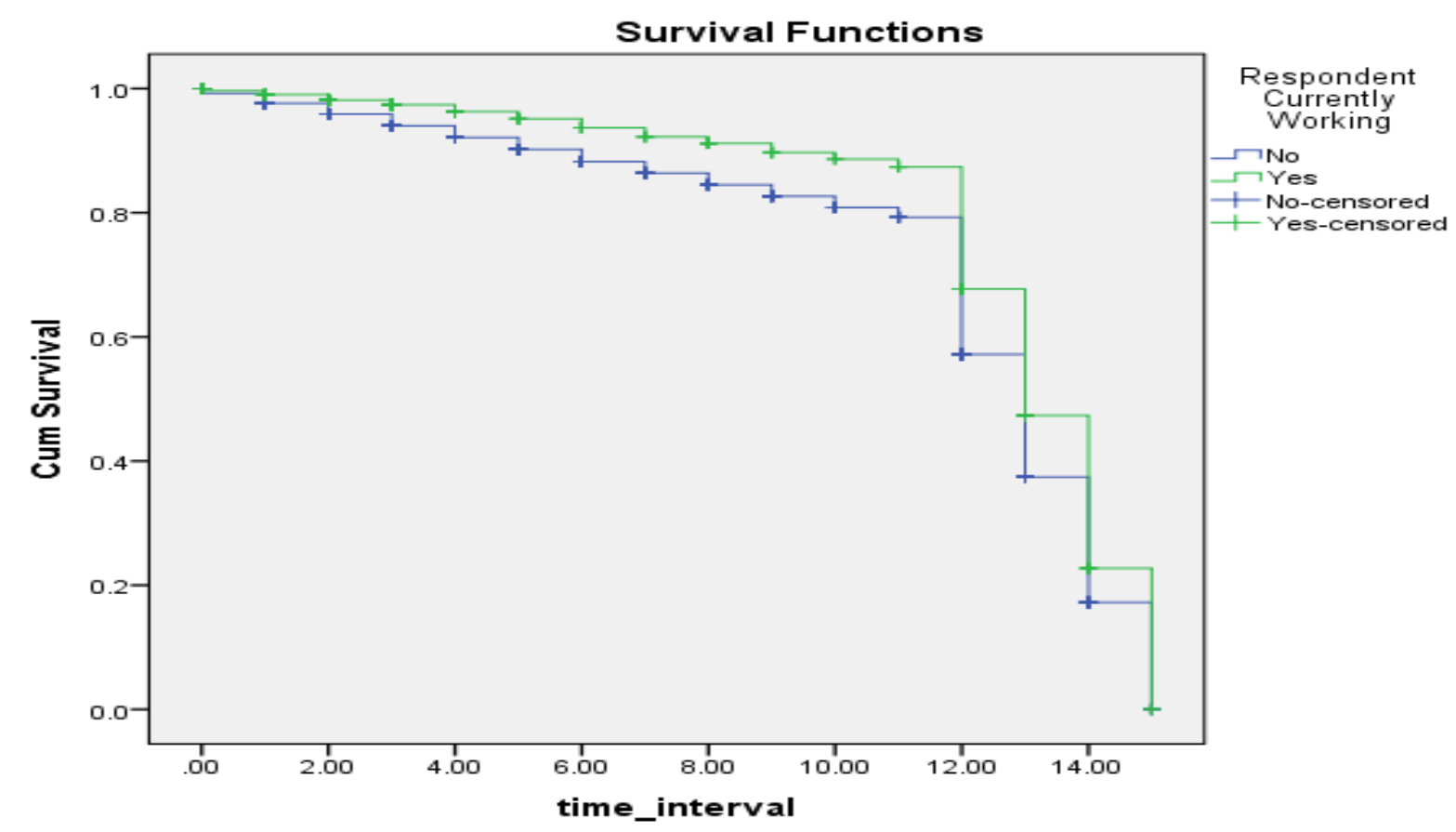

Figure 1. Test of equality of survival distributions for the different levels of Mother's Current Work status

Table 3 Survival status of under-five year of children in India

\begin{tabular}{llll}
\hline Total & N of & \multicolumn{2}{l}{ Censored } \\
\hline $\mathrm{N}$ & Event & $\mathrm{N}$ & Percent \\
45231 & 2054 & 43177 & 95.4 \\
\hline
\end{tabular}

Among the 45231 children, 2054 children under five years lost their life under attaining their fifth birthday. About $95 \%$ of the cases were censored in this analysis. The difference in the risk of work status of mothers were very clear from the above figure.

\section{DISCUSSION}

The life table was calculated for the five years of life of children. In India 259627 birth were reported during 2015-16 among which 30 deaths/1000 live births were happened during their first month of life. This means that one in 33 live births died during the neonatal period. Under reporting of infant deaths may happen, in particular, is usually most severe for deaths, which occur very early in infancy and age heaping is also an existing problem. The KM curve displays the disparity in the survival status of children of working and nonworking mothers in India. It is also evident that maternal employment has appositive impact on the survival status of children. 
Working mothers with a proper adjustment between workplace and family can provide quality care for their children (Poduval et al., 2009). Other evidence from developed settings suggests that maternal employment reduced the risk of small birth size and infant mortality. Earlier research from India showed that the mortality rate of children under the age of 5 is more for the employed mother (Sunita et al., 1998).This study result is contradictory to the findings of Sunitha et al, in 1998.

\section{CONCLUSION AND SUGGESTION}

In nutshell, we can conclude that the hazard rate of probability density function were very high during the first month of life that revealed that concentration of a large number of deaths occur in the first month. In addition, the survival chance of children under -five years of age continuously increases over periods. Moreover, the impact of maternal employment in the survival status of their children are positive and by creating better job opportunities for women may increase the financial status of family and thereby increase the accessibility of better health care services for survival of their children.

\section{REFERENCES}

1. Engle, P. L. Maternal work and child care strategies: nutritional effects. Child Development 62, 954-965.

2. Glezer, Mothers in the workforce, Fam Matters. 1988 Aug;(21):30-4

3. Hoffman, L.W. (1989) Effects of maternal employment in the two-parent family. American Psychologist 44(2), 283-292.

4. Jayita Poduval and Murali Poduval,Mens Sana Monogr. 2009 Jan-Dec; 7(1)

5. Kishor Sunitha, Mother's Employment and Infant and Child Mortality in India, National Family Health Survey Subject Reports, Number 8 • April 1998

6. United Nations, Sustainable Development Goals (SDG). Washington, DC; 2015 